\title{
Self-punitive behavior : Effects of percentage of punishment on extinction of escape and avoidance responses
}

\author{
LEE BENDER AND KENNETH B. MELVIN
} UNIVERSITY OF ALABAMA

In general, vicious-circle behavior was an increasing function of the percentage of punished trials, and avoidance-trained Ss showed more punishment-induced facilitation (and resistance to "regular" extinction) than escape-trained $S$ s.

Several experiments have indicated that avoidance responses are more resistant to extinction than escape responses. In the "vicious circle" paradigm, punishment generally facilitates an ongoing escape or avoidance response during extinction. Data from an escape situation indicated that this self-punitive behavior was an increasing function of the percentage of punished trials (Melvin, 1964). The purpose of the present study was to investigate the effects of type of training and percentage of punished extinction trials on vicious-circle behavior.

Method

Subjects and Apparatus. The Ss, 72 male hooded rats from Rocklands Farms, were 90-120 days old.

The apparatus was described in detail by Melvin, Athey, \& Heasley (1965). Major components of the apparatus were a duplex start box, a straight alley, and a wooden goal box. Alley and total response times were recorded to the nearest .01 sec. Goal box entrance terminated the buzzer CS.

Procedure. After $24 \mathrm{~h}$ food deprivation, $\mathrm{S}$ was handled. Following $10 \mathrm{~min}$ of apparatus exploration, $\mathrm{S}$ was assigned randomly to one of two training groups. Escape training consisted of two pretraining trials and 12 training trials. On Trials 1 and 2, $S$ was placed at a distance of $2 \mathrm{ft}$ and $1 \mathrm{ft}$, respectively, from the goal box into which he escaped. On training trials, trapdoor release turned on a $50 \mathrm{~V}$ ac shock (through a $10 \mathrm{~K}$ ohm resistor) and a buzzer. $S$ remained in the goal box for $30 \mathrm{sec}$. In avoidance training, trapdoor release turned on the CS for $5 \mathrm{sec}$, followed by $50 \mathrm{~V}$ shock. The acquisition criterion was five consecutive avoidances.

Extinction. Immediately after training, S was randomly assigned to one of four conditions: $0 \%, 10 \%$. $50 \%$, or $100 \%$ of punished "extinction" trials. The punishing shock was located in the 2nd and 3rd foot of the $4 \mathrm{ft}$ alley when scheduled. These procedures formed the following groups: A0, A10, A50, A100; E0, E10, E50, and E100. For the partially punished groups, shock was scheduled randomly within each block of 10 trials. The shock intensities were the same during extinction as in training, as were other procedural details except where noted. Seventy extinc- tion trials were given; however, if $S$ falled to enter the goal box within $60 \mathrm{sec}$, his testing ceased and scores of $60 \mathrm{sec}$ were recorded.

Results

Both tasks were easily learned and Ss reached asymptote in 8 to 12 trials. A 2 by 4 analysis of variance based on each S's median running speed of the last three acquisition trials showed that escape training led to significantly faster asymptotic alley speed than avoidance training ( $F=11.03, d f=1 / 64, p<.01$ ). Mean alley speeds of groups formed on the basis of percentage of punished extinction trials were not significantly different.

Number of Ss extinguished. The following numbers of $\mathrm{Ss}$ in each group met the extinction criterion: $\mathrm{A} 0-2, \mathrm{A10}-2, \mathrm{A50}-0, \mathrm{~A} 100-0$, and $\mathrm{E} 0-6, \mathrm{E} 10-3$, E50-3, E100-0. In general, fewer avoidance-trained Ss extinguished than escape-trained Ss. A median test comparing escape and avoidance Ss (excluding the $100 \%$ groups, which are identical) was significant $\left(x^{2}=6.87, d f=1, p<.01\right)$. A median test over the four percentage groups showed that the number of Ss extinguished was a significantly decreasing function of the percentage of punished trials $\left(x^{2}=5.49, \mathrm{df}=3, \mathrm{p}\right.$ $<.01)$. A similar test excluding nonpunished Ss approached significance $\left(x^{2}=5.49, \mathrm{df}=2, \mathrm{p}<.10\right.$ ).

Alley speed. Figure 1 shows the mean alley speed for each of the eight groups, collapsed across blocks of trials. It is clear that the punishment schedules yielded faster alley speed than no punishment. Analysis of variance showed that Ss receiving the lowest percentage of punished trials during extinction (Groups

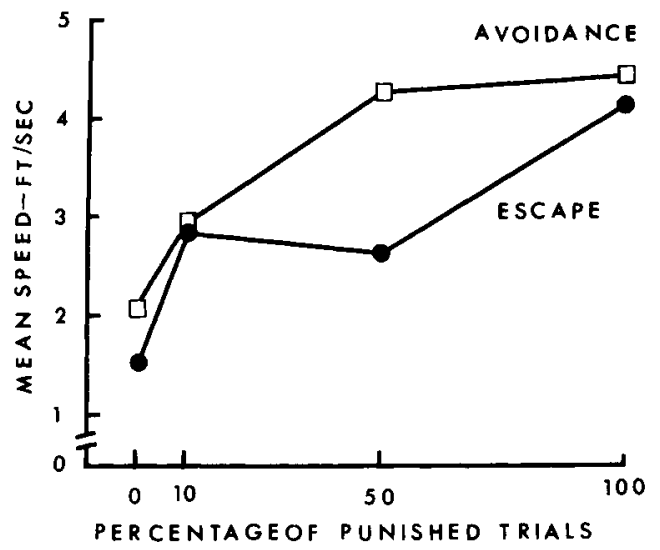

Fig. 1. Mean alley speed for the eight groups as a function of percentage of punished trials. 


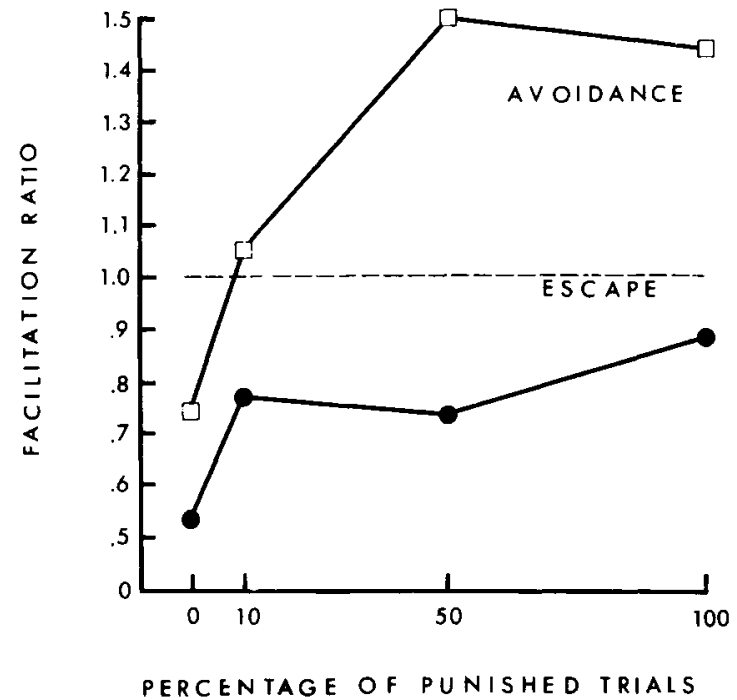

Fig. 2. Facilitation ratios for the eight groups. A ratio of 1.0 indicates equivalent speeds for asymptotic acquisition speed and speed during extinction.

A10 and E10) were significantly faster than unpunished Ss $(F=4.72, d f=1 / 32, p<.05) .{ }^{1}$ Furthermore, running speed during extinction increased significantly as a function of the percentage of punished trials ( $F=10.36$, $d f=3 / 64, p<.001)$. This effect was significant even when the control groups were excluded. Also significant were the interaction of training procedure with blocks, punishment percentage with blocks, and the triple interaction. These interactions reflect three major trends: (1) punished groups run at a stable speed across the 70 trials except for (2) the A50 group which shows a gradual increase in speed and (3) the control group, which shows a progressive decline in speed.

Facilitation ratio. The curves in Fig. 2 are based on the "facilitation ratios" for each of the eight groups-a relative measure of punishment-induced facilitation. Each point represents a median of nine ratios; each ratio is one $S^{\prime}$ 's median speed during extinction for seven blocks of 10 trials divided by his median speed for the last three acquisition trials. Punishment produced a relatively greater facilitative effect upon avoidance-trained Ss than escape-trained Ss. Mann-Whitney $U$ tests showed this type of training effect was significant for the 50\% and $100 \%$ punishment groups. The facilitation ratio was the only measure which showed Group A100 significantly superior to Group E100. In general, this relative facilitation effect was an increasing function of the percentage of punished trials. A Kruskal-Wallis anal- ysis of variance found this effect to be highly significant for the avoidance-trained Ss $(H=15.43$, df $=3, p<.01$ ) but not for the escape-trained Ss. However, Group E10 showed significantly more facilitation than the E0 control group $(\mathrm{U}=9.0, \mathrm{p}<.02)$.

\section{Discussion}

In general, avoidance-trained Ss were more resistant to punishment-extinction than escape-trained Ss, thus confirming and extending the findings of Hurwitz, Bolas, \& Haritos (1961) and Beecroft \& Brown (1967). The superiority of avoidance-trained Ss was reflected in both speed and in the number of Ss extinguished. However, while this effect was apparent with partial punishment, it was not seen with $100 \%$ punishment (except for the facilitation ratio measure). It appears that under optimal conditions, e.g., 100\% punishment, the type of training procedure is not as important as it is under less favorable conditions. In the nonpunished conditions, avoidance-trained Ss extinguish at a slower rate than escape-trained Ss, a finding which confirms earlier results (e.g., Sheffield \& Temmer, 1950).

In general, resistance to extinction was found to be an increasing function of the percentage of punished extinction trials. These data confirm Melvin's (1964) finding in an escape situation and extend this relationship to an avoidance paradigm. However, the facilitative effect was shown even with $10 \%$ punishment-extinction, indicating that the present conditions were very effective in producing the vicious-circle phenomenon. Previous experimenters obtained reliable self-punitive behavior in an escape paradigm only with percentages of punished trials of $33 \%$ or $67 \%$ (Gwinn, 1949; Melvin, 1964). Our data indicate that as other conditions become more favorable, the percentage of punished trials required for vicious-circle behavior decreases.

\section{References}

BEECROFT, R. S., \& BROWN, J. S. Punishment following escape and acoidance training. Psychon. Sci., 1967, 8, 349-350.

GWINN, G. T. The effects of punishment on acts motivated by fear. J. exp. Psychol., 1949, 39, 260-269.

HURWITZ, H. M. B., BOLAS, D., \& HARITOS, M. Vicious circle behavior under two shock intensities. Brit. J. Psychol., 1961, 52, 377-383.

MELVIN, K. B. Escape learning and "vicious circle" behavior as a function of percentage of reinforcement. J. comp. physiol. Psychol., $1964,58,248-251$.

MELVIN, K. B., ATHEY, G. I. JR., \& HEASLEY, F. H. Effects of duration and delay of shock on self-punitive behavior in the rat. Psychol. Rep., 1965, 17, 107-112.

Note

1. A figure showing alley speed for groups over seven blocks of trials is shown in Lee Bender's M. A. thesis. 